\title{
Pre-service Science Teachers' Discrimination Level of Science and Pseudoscience
}

\author{
Murat Berat Uçar ${ }^{1 *}$ Elvan Sahin ${ }^{2}$ \\ ${ }^{1}$ Department of Mathematics and Science Education, M. R. Faculty of Education, Kilis 7 Aralik University, Kilis, Turkey, 2Department of Mathematics \\ and Science Education, Faculty of Education, Middle East Technical University, Ankara, Turkey
}

*Corresponding author: berat@kilis.edu.tr

\section{ABSTRACT}

This quantitative study aimed to examine Turkish pre-service science teachers' beliefs regarding the demarcating between science and pseudoscience. Participants completed the Science and Pseudoscience Distinction Scale. Data collected from the 123 pre-service science teachers were examined based on the dimensions of the instrument, namely science as a process of inquiry (SCI), demarcating between science and pseudoscience, and pseudoscientific beliefs (PS). This study found that these pre-service science teachers generally did not hold strong beliefs on distinguishing science and pseudoscience. Their beliefs regarding SCI were not highly favorable. Moreover, this study revealed that they had some PS. Considering the role of gender and year in the program, the results of two-way MANOVA indicated that there was no statistically significant difference on the related belief constructs for these pre-service science teachers. Thus, the present study intended to shed light on pre-service science teachers' mindsets about identifying accurate scientific information rather than pseudoscientific confusions that could aid preparing scientifically literate students. It was shown that their teacher education program did not facilitate favorable beliefs. This study highlights some potential areas for further exploration of addressing pre-service science teachers' discrimination skills of science and pseudoscience.

KEY WORDS: pseudoscience; demarcation of science; pre-service science teacher

\section{INTRODUCTION}

ᄂ he rapid development of science and scientific information has brought society and scientists into conflict from time to time. The necessity and ability of obtaining more and more information relying on a reliable source such as science have sometimes led to the misunderstanding or even the manipulation of science. Some misleading manipulations have been illustrated as metaphysical tenets, ideologies, conspiracy theories, and so on (Turgut, 2009; Uslu, 2011; Wallis, 1985). In this manner, different ideas from thinkers and scientists have emerged over the last two centuries to initiate discussions and to reach a consensus on what things we do that we call science, as well as what we should exclude from science. As a result, the demarcation between science and pseudoscience (DEM) has become a significant issue as people now have easier access to information as compared to past decades. Moreover, it has been widely observed that individuals have the tendency to accept something declared as scientific or labeled as scientifically proven. For example, Forer (1949) concluded that people have disposition of accepting vague or trivial personality statements. Wyman and Vyse (2008) reported that some people believe complex and vague statements when they think that these statements come from a systematic procedure. This is referred to as the "Barnum effect." Allum (2011) noted that some individuals undergo a mistaken mental reasoning along the lines of "It sounds complicated - it must be scientific!" As the Barnum effect implies how people tend to accept complex but erroneous information as scientific, some teachers and educators may also have difficulties in deciding on whether information is scientific or non-scientific. However, it is essential that pre-service science teachers who are candidates responsible for teaching science to future generations should know scientific processes as well as what is classified as science and non-science, pseudoscience, and paranormal in accordance with the goals of science education (e.g., Martin, 1994; Mugaloglu, 2014).

Since science teachers have an influence on their students' scientific viewpoints (Lederman, 1999), both science teachers and science teacher candidates are required to have adequate knowledge and skills concerning the nature of science which may help them to demarcate science and pseudoscience (Afonso and Gilbert, 2009; Lederman, 2007; Saka and Surmeli, 2017). In this regard, pre-service science teachers are expected to comprehend definitions, scopes, and content of science and should have awareness of what kind of claims or phenomena should be excluded from science. Accordingly, as science education aims to prepare scientifically literate individuals who can also discriminate science from nonscience, science education may contribute to creating a less unscientific thinking society (Hurd, 1998; Metin and Ertepinar, 2016). Thus, defining the scopes and content of science and 
the discrimination of science from non-science could be considered among the crucial issues in research studies in the field of science education. In the light of this literature review, we intended to investigate ways to prepare scientifically literate teachers in having the required competencies to educate their pupils by addressing their beliefs in pseudoscience, $\mathrm{SCI}$, and demarcating between science and pseudoscience.

\section{DEFINING SCIENCE}

To answer the question of what is science, defining science is necessary. As a general definition, the word "science" originated from the Latin word "scientia" meaning knowing or knowledge (Lakatos, 1981). Aristotle describes science as knowing the reason why an object exists (Aristotle, trans. 1996). According to him, metaphysical knowledge is the only source that can define science. Although Aristotle focused on metaphysical knowledge, modern scientist and thinkers like Kant reject metaphysics and allege that all knowledge begins with experiences so that science cannot exist without experiences or experiments (Kant, 1855). This can be accepted as one of the first attempts to determine a limit for science. Similarly, Popper (1957) described science as finding a reasonable explanation on what is needed to be explained. Later, Popper (1963) modified his description as a conscious task that solves a problem through the construction of a theory, which scientists pay attention to first. In other words, science begins from a problem, rather than an observation. According to Dorland's Medical Dictionary (2007), science is the set of knowledge that looks for establishing general laws to connect two or more facts. A more recent definition of science comes from the Cambridge Dictionary Online (n.d.):

Knowledge from the careful study of the structure and behaviour of the physical world, especially by watching, measuring, and doing experiments, and the development of theories to describe the results of these activities. [Def. 1]

As noted above, these definitions can vary from person to person or from institution to institution, and as a result, there is no universal definition of science.

Hence, why does a definition of science matters to us at all? This question may have been popular among the philosophers of the past, but we would argue that people interested in science should also be curious about this question. When compared to the past, people now have easier access to information. Among the tremendous amount of information, people must try to select and follow accurate and reliable sources. In this aspect, individuals tend to prefer to accept scientific information because they think that this information and methods are expected to be proved and correct. The following statements, for example, may be perceived as scientifically trustworthy information in $\mathrm{TV} /$ social media advertisements and daily rumors by people: "Scientists say that this product is safe to use!" "According to our experts, these meditation sessions will definitely ease your problems," or "based on the astronomical observations, the planets' positions bring new opportunities to you and your family, so don't miss them!" As understood from these examples, some use or pretend to use science-related tools or explanations to strengthen their claim and to make people believe in their methods or products that they advertise to sell.

If there is a chance to deceive people using some misleading expressions related to science, then, how can we determine science from non-science? To answer this, question requires us to refer to one of the characteristics of science. That is, it is necessary to accept that science is and will likely to continue to evolve since the nature of science is tentative, open to change as new evidence and advancements in theory and technology discovered, or shifts in the directions of established research programs (Lederman, 2007). This continuing evolution makes science a process of inquiry and development. In this process, some part of it may be rejected, replaced, or revised (like refuting some part of Newtonian physics by the emerging of relativity physics). This implies that science is open to expanding and renewing itself by investigating, experimenting, and criticizing. Likewise, there are some hypotheses or propositions in science, which have not yet been determined to be true or false. For instance, the reason of the extinction of dinosaurs has been explained by more than one hypothesis that does not mean that not all the alternative hypotheses (we are not able to determine a decisive reason of it yet) are scientific because they are depended on scientific methods and explanations. Thus, they are labeled as neither true nor false propositions. If they were refuted someday, then they would become erroneous science (Sagan, 2011). They would be claims that are determined to be false in time.

\section{SCIENCE VERSUS PSEUDOSCIENCE}

We also need to focus on being able to distinguish real science from non-science. Unlike the science or erroneous science, non-science covers beliefs, ideology, philosophy, or the point of view of people. The most popular term for this is "pseudoscience." This term became popular when Popper (1963) discussed it in his paper "conjectures and refutations: The growth of scientific knowledge." He stressed that pseudoscientific methods or knowledge both pretended to rely on scientific methodology and remain closed to falsifying, refuting, or testing as Freud's Psychoanalysis or astrology. It is impossible to test these in any experimental set because the results of their studies are either limited to their experimental setup or setting up an experiment is not possible (i.e., astrology). Moreover, Popper also pointed out that pseudoscience may utilize observations, experiments, and induction. This makes easier for supporters or naïve minds to follow their claims. That is, it is likely one which is able to find supportive evidence for even the most exaggerated phenomenon. Applying a pseudoscientific explanation, using uncontrolled experiments, and presenting suitably selective samples may help to trick people and lead them to be consider what is presented as scientific. According to Popper, pseudoscience usually tries to suit data and facts to theory 
instead of applying theory to the data and facts. It first adopts an ideology, prejudgment or belief, and then endeavors to situate the findings in accordance with the pseudoscientific theory.

An important aspect of Popper's criteria for being scientific is related to falsifiability. Popper stated that any information or idea becomes pseudoscientific if there was no way to falsify it practically or theoretically. He argued that scientists should ask themselves under which conditions does our hypotheses become false rather than under which conditions does our hypotheses become verified by data. Accordingly, Popper considered this falsifiability as a criterion for scientific reasoning. In other words, a falsified hypothesis that is scientific does not have to be meaningless. Sometimes, a part of a theory fails to explain a phenomenon or creates a paradox. In this situation, alternative theories that encompass the answers of restricted parts of a theory may replace the original theory (i.e. Newtonian physics vs. Einstein's relativity). Then, the latter theory would become more scientific one. However, theories occasionally need ad hoc auxiliary explanations (Popper, 1963). An ad hoc refers to extra explanation for strengthen a theory in case of a problem or conflict against an existing fact. Using ad hoc is rarely inevitable in science although it is a sign that the process is getting away from being scientific (Popper, 1963). Thus, scientific theory should be close to intervening one's interpretations and ideology.

Even though Popper contributed much to the science philosophy literature, some debate has risen against his ideas. One of them is Thomas Kuhn's critiques. Unlike Popper's falsifiability criterion, Kuhn (1970) thinks that normal science cannot be tested in accordance with falsifiability. He suggested that the purpose of science was to solve the puzzle. To do this, current theory is determined as a paradigm which helps to solve the puzzle. Therefore, Kuhn's normal science is founded on some agreements and beliefs called paradigms. In the matter of pseudoscience, Kuhn (1970) gives astronomy and astrology as examples. An astronomer's hypothesis can be transformed into a puzzle solved by falsifying with new observations and hypotheses. However, an astrologer's hypothesis is never suitable for problem-solving because there is no effort to change the theory or hypothesis. Thus, astrology becomes a pseudoscience. Furthermore, Kuhn agreed with Popper in determining the demarcation of science with theory open to development, change, and possibility of being criticized in light of new data or facts.

Like Popper and Kuhn, Thagard (1978) also argued why astrology was a pseudoscience. To him, Popper and Kuhn's criteria were insufficient, and therefore, new criteria were necessary. Thagard alleged that demarcation criteria should consist of theory (testability, verifiability, falsifiability, and suitability for puzzle solving), community (confirmation of disconfirmation efforts by the corresponding science community), and historical context (like Kuhn's ideas). In short, the theory or discipline is not scientific if it does not progress more than its alternatives over time, and society or people corresponding do not contribute to it for progressing or solving the problems or closed to others evaluations to test it.
To sum up, although there is not a decisive consensus on a definition of science (Turgut, 2009) as well as the question of which explanations can be accepted as scientific (Lambert and Brittan, 1992), some criteria have been considered by scientific and educational communities. Yet, basic demarcation borders for science to distinguish non-science can be exemplified as falsifiability, testability, openness to critics and refutations, suitability for redoing, and appropriateness of general acceptance of current science community (Akerson and Volrich, 2006; Ayvaci and Bag, 2016; Popper, 1957; Thagard, 1978), puzzle-solving (Kuhn, 1981), and research programs (Lakatos, 1981). Specifically, much of the previous research has focused on determining and discussing the PS of students as well as teacher candidates to demarcate science from pseudoscience.

\section{LITERATURE REVIEW}

Although many studies have reported the existence of individual's PS such as conspiracy theories, paranormal activities, ufology, believing in ghosts, and water dowsing (Afonso and Gilbert, 2009; Brotherton et al., 2013; Garrett and Cutting, 2012; Lederman, 2007; Lobato et al., 2014; Martin, 1994), there is a limited number of studies regarding the PS of pre-service teachers as compared to general pseudosciencerelated studies. For example, Turgut (2009) stressed that pre-service teachers were likely to leave decision-making processes on any scientific issue to others like experts in the field without endeavoring personal critical judgments related to the issue. Moreover, Turgut's findings revealed that pre-service teachers were less successful in discriminating science from pseudoscience. Similarly, in Metin and Ertepinar's study (2016), science teacher candidates conveyed PS related to earthquakes despite taking geology and nature of science courses. Some of the participants failed to put forward scientific explanations about why scientific evidence was important to support not believing pseudoscience as well. These studies indicates that many pre-service teachers struggle with pseudoscientific confusions despite taking subject-matter knowledge and science courses. Accordingly, Ayvaci and Bag (2016) pointed out that, although pre-service classroom teachers have beliefs of curiosity and research related to science, their background about the nature and characteristics of science remains at a low level. Moreover, they tend to hold some PS; for example, they stated that explaining a metaphysical phenomenon such as a miracle or religious incident based on science is impossible.

In a qualitative study by Kaplan (2014), most of the participating pre-service science teachers taking an astronomy course confused astrology and astronomy as if they were both scientific. Another qualitative study (Turgut et al., 2016) indicated that pre-service early childhood teachers confused the terms of science and technology and believed that science had a realistic and positivist approach because of emphasizing provability of science.

Based on the philosophical discussion of pseudoscience and related works regarding to pre-service science teachers, it is 
significant to educate future science teachers to be capable of discriminating science and pseudoscience effectively. Investigating their condition related to pseudoscientific demarcation capabilities will give clues about their developments as teacher candidates. Therefore, this study is expected to contribute to both related literate and teacher trainers at education faculties. The study covers two research questions as follows:

1. What are pre-service science teachers' beliefs toward SCI, DEM, and PS?

2. Do pre-service science teachers' beliefs toward SCI, DEM, and PS differ with respect to gender and year in the program?

\section{METHODS}

\section{Sample}

Volunteer pre-service science teachers at a public university in Southeastern Anatolia Region of Turkey participated in this study, as shown in Table 1. Most of the 123 participants were female $(\mathrm{n}=102)$, which is typical gender distribution of preservice science teachers in Turkey (Koray, 1993; Statistics of Turkish National Ministry of Education, 2013). The frequency distribution of the participants is given in Table 1.

\section{Instruments}

A 5-point Likert-type instrument, called the Science-Pseudoscience Distinction Scale, was used to determine pre-service science teachers' (PST) beliefs regarding the DEM. The scale was originally developed by Oothoudt (2008) and covered 32-items. ATurkish version of the scale was prepared by Kirman et al. (2013) and consisted of 23-items. Based on the reliability and validity analyses, a 17-item instrument containing three dimensions was retained. The results of confirmatory factor analysis are presented in Table 2. In terms of model parameters, all the indexes were found to be in an acceptable range (Hu and Bentler, 1999). In terms of reliability, Cronbach's alpha coefficients were $0.62,0.61$, and 0.67 for the subdimension belief in PS, demarcating between science and pseudoscience, and SCI, respectively.

\section{Data Analysis}

To assess pre-service science teachers' beliefs regarding demarcation science and pseudoscience, the mean scores and standard deviations were calculated through descriptive statistics. Moreover, a two-way MANOVA was used to investigate the role of gender and year in the program on the three dependent variables in the present study. Preliminary analyses showed that there was no violation of any of assumptions of MANOVA analysis. For example, normality was found to be appropriate when checked with SkewnessKurtosis values range of $[-2,+2]$. In addition, there was no violation of homogeneity of variance-covariance matrices, Box $\mathrm{M}=55.56, F=0.926, \rho>0.05$. For the three dependent variables, a non-significant result was obtained by Levene's tests. In addition, there were no multivariate outliers (Mahal. distance $<$ critical value). Finally, linearity was satisfied through matrix of scatterplots. These findings implied that MANOVA analysis could be proceeded based on the data.

\section{FINDINGS}

\section{Descriptive Statistics}

As presented in Table 3, the pre-service science teachers had stronger beliefs regarding SCI when compared to the demarcation of science and pseudoscience (DEM) or PS. That is, their understanding of experimental designs and scientific methods was more favorable. To illustrate, their responses were compatible with the nature of science, which are the tentative structure of scientific knowledge, the necessity of scientific inquiry for supporting a hypothesis, and the replicability of scientific experiments. However, the level of their SCI was not great $(\mathrm{M}=3.56)$, implying that these pre-service science teachers did not possess beliefs regarding the nature of science concepts and the structure of scientific knowledge. In terms of DEM level, these pre-service science teachers had difficulty in discriminating science from pseudoscience, which reflects that their knowledge of demarcating science was not high. The participants' responses showed that they were somewhat able to demarcate pseudoscientific ideas from science like astrology and palm reading. Similarly, they agreed with the idea that placing magnets on the body as a means to heal the body was a valid medical process. Apart from the SCI and DEM beliefs, the level of pre-service science teachers' PS beliefs was found to be moderate, suggesting that they hold PS beliefs. They supported items like "science may include some topics like ghosts, the supernatural, aliens, etc." This suggests that these pre-service science teachers held some PS. Thus, although pre-service science teachers were somewhat aware of the processes of science, they also held PS, and they were not so successful in distinguishing what could be classified as science and pseudoscience.

With respect to gender, female participants were slightly better in demarcating science and pseudoscience based on the mean scores. On the other hand, year in the program did not show much difference in beliefs related to SCI, DEM, and PS. Thus,

\begin{tabular}{ll}
\hline $\begin{array}{l}\text { Table 1: Frequency and percentages of participants' } \\
\text { gender and year in the program }\end{array}$ \\
\hline Variables & \multicolumn{1}{c}{$\mathbf{n}(\%)$} \\
\hline Gender & \\
$\quad$ Female & $102(82.9)$ \\
Male & $21(17.1)$ \\
Year in the program & \\
$1^{\text {st }}$ year (freshman) & $20(16.3)$ \\
$2^{\text {nd }}$ year (sophomore) & $44(35.8)$ \\
$3^{\text {rd }}$ year (junior) & $32(26)$ \\
$4^{\text {th }}$ year (senior) & $27(22)$ \\
Total & $123(100)$ \\
\hline
\end{tabular}

Table 2: Confirmatory factor analysis results of the scale

\begin{tabular}{lccccc}
\hline $\boldsymbol{\chi} 2 / \mathrm{DF}$ & $\boldsymbol{\rho}$-value & CFI & GFI & SRMR & RMSEA \\
\hline 1.412 & 0.003 & 0.85 & 0.88 & 0.08 & 0.06 \\
\hline
\end{tabular}


gender did not seem as a remarkable variable in pre-service science teachers' beliefs related to the science, pseudoscience, and demarcation of these.

\section{Inferential Statistics}

Two-way MANOVA (Table 4) did not show any statistically significant difference for gender, educational level, and interaction effect of gender and educational level on any of the dependent variables. In other words, the role of gender and educational level on dependent variables of SCI, DEM, and PS was not statistically significant.

\section{DISCUSSION AND CONCLUSION}

This study aimed to investigate pre-service science teachers' level of demarcating science and pseudoscience as well as the role of gender and year in the program. According to the results, these pre-service science teachers seemed to have difficulties in understanding the structure of science, scientific methods, and scientific experimenting. Specifically, they did not perform well about processes in scientific investigations such as considering all variables in the study or defining hypothesis. Moreover, they seemed to remain undecided related to sharing results of scientific investigations with everybody, controlling of published results of scientific investigations. Such findings could be associated with pre-service science teachers' lack of

\begin{tabular}{|c|c|c|c|}
\hline Variables & Minimum & Maximum & Mean \pm SD \\
\hline \multicolumn{4}{|l|}{ SCI } \\
\hline Female & 2.11 & 4.44 & $3.57 \pm 0.49$ \\
\hline Male & 2.56 & 4.44 & $3.54 \pm 0.84$ \\
\hline Total & 2.11 & 4.44 & $3.56 \pm 0.48$ \\
\hline $1^{\text {st }}$ year (freshman) & 3.00 & 4.33 & $3.72 \pm 0.37$ \\
\hline $2^{\text {nd }}$ year (sophomore) & 2.11 & 4.44 & $3.48 \pm 0.5$ \\
\hline $3^{\text {rd }}$ year (junior) & 2.78 & 4.44 & $3.55 \pm 0.43$ \\
\hline $4^{\text {th }}$ year (senior) & 2.39 & 4.44 & $3.61 \pm 0.56$ \\
\hline \multicolumn{4}{|l|}{ DEM } \\
\hline Female & 1.60 & 5.00 & $3.49 \pm 0.72$ \\
\hline Male & 2.00 & 4.80 & $3.35 \pm 0.84$ \\
\hline Total & 1.60 & 5.00 & $3.46 \pm 0.74$ \\
\hline $1^{\text {st }}$ year (freshman) & 2.60 & 4.80 & $3.58 \pm 0.69$ \\
\hline $2^{\text {nd }}$ year (sophomore) & 1.60 & 5.00 & $3.62 \pm 0.83$ \\
\hline $3^{\text {rd }}$ year (junior) & 2.40 & 4.20 & $3.24 \pm 0.49$ \\
\hline $4^{\text {th }}$ year (senior) & 2.00 & 5.00 & $3.39 \pm 0.82$ \\
\hline \multicolumn{4}{|l|}{ Belief in PS } \\
\hline Female & 1.00 & 5.00 & $3.03 \pm 0.79$ \\
\hline Male & 1.00 & 4.25 & $3.04 \pm 0.94$ \\
\hline Total & 1.00 & 5.00 & $3.03 \pm 0.81$ \\
\hline $1^{\text {st }}$ year (freshman) & 2.00 & 4.50 & $3.22 \pm 0.83$ \\
\hline $2^{\text {nd }}$ year (sophomore) & 1.00 & 4.50 & $3.02 \pm 0.76$ \\
\hline $3^{\text {rd }}$ year (junior) & 1.25 & 5.00 & $2.95 \pm 0.78$ \\
\hline $4^{\text {th }}$ year (senior) & 1.00 & 5.00 & $3.01 \pm 0.93$ \\
\hline
\end{tabular}

SCI: Science as a process of inquiry, PS: Pseudoscientific beliefs, DEM: Demarcating between science and pseudoscience sound understanding of the nature of science as supported by Bell and Lederman (2003) and Lederman (2007). This implies that their understanding of the science as an inquiry should be developed more effectively. Moreover, it is essential to stress that pre-service science teachers should have a great understanding of the nature of science as they are expected to teach science rather than non-science.

Regarding the discriminating of science and non-science, these pre-service science teachers were not good at the differentiation of real science from the pseudoscience in the given items. They may have confused pseudoscientific situations in the given items with their previous knowledge. As unfamiliarity of pseudoscience and pseudoscientific examples may have led to confusion in these pre-service science teachers' minds, their failing in the demarcating of science and pseudoscience might have been resulted from this low background related to pseudoscience. In parallel with earlier research (Turgut, 2009), pre-service science teachers struggled in diagnosing premises as to whether they are scientific or pseudoscientific. This might be considered as indication of lack of effort in preservice science teachers eliminating PS or that it may be due to the lack of knowledge about what science is and what it is not. While it is sometimes hard to discriminate being scientific, however, the way and methods of a procedure reflect whether it is scientific or not. Thus, pre-service science teachers should be taught scientific processes besides subject matter knowledge and the nature of science.

Apart from understanding science as an inquiry of process, believing in ghosts, alien visiting, forces beyond scientific understanding, or the natural laws were held by these preservice science teachers. This implies that these pre-service science teachers do believe things that are considered scientifically unacceptable rather than phenomena or facts that are scientifically accepted. Since a higher mean score indicates that pre-service science teachers held low PS, it is clear to see that they had PS at some degree. This finding was also consistent with Gul's study (2015), probably resulting from low science background and lack of knowledge related to nature of science or unfamiliarity of pseudoscientific claims or situations. As Kirman et al. (2013) emphasized, a teacher who fails in discriminating science and pseudoscience and knowing scientific methods is unlikely able to teach science correctly.

Despite few exceptions in the literature, gender did not play any role in understanding SCI, PS, and demarcating science and pseudoscience (Kirman et al., 2013) as reported in this study. The findings revealed that the differences between males

\begin{tabular}{lccccc}
\hline \multicolumn{3}{l}{ Table 4: Two-way MANOVA results } & & & \\
\hline Variables & $\begin{array}{c}\text { Wilk's } \\
\text { lambda }\end{array}$ & $\mathbf{F}$ & df & df error & $\mathbf{\eta}^{2}$ \\
& 0.99 & 0.29 & 3 & 113 & 0.01 \\
\hline Gender & 0.88 & 1.65 & 9 & 275 & 0.04 \\
Year in the program & 0.87 & 1.75 & 9 & 275 & 0.08 \\
Gender * year in the program & & & & &
\end{tabular}


and females were not statistically significant. This reflects that not only male pre-service science teachers but also female pre-service science teachers had beliefs in ghosts, aliens, the supernatural, suffered from identifying and discriminating science and pseudoscience, lack understanding of the nature of science, and content of scientific investigations. On the other hand, the year in the program did not play a significant role in pre-service science teachers' PS, DEM, and SCI, which is consistent with some previous research (Kirman et al., 2013). It was expected that the junior and senior pre-service science teachers would have had a better understanding of the beliefs of SCI and DEM and less PS. One of the possible implications of this study is that the course in the $3^{\text {rd }}$ year "Nature of Science and History of Science" does not support pre-service science teachers discriminating between science and pseudoscience effectively.

The results indicate that the demarcation of science and pseudoscience by these pre-service science teachers is problematic due to holding PS rather than scientific. Not only pre-service science teachers but also other teaching profession areas such as primary school teaching, physics, chemistry, and biology teaching may suffer from not being able to distinguish science from pseudoscience (Gul; 2015; Senler and Irven, 2016). Since demarcation can be regarded as a problem related with teaching all science branches, further research would shed light into the status of teacher candidates in other science areas against pseudoscientific scenarios or claims. Nonetheless, a larger sample than the sample of this study along with data triangulation of instruments or participants would make a greater contribution in future studies.

\section{LIMITATIONS AND RECOMMENDATIONS}

Due to small sample size, this study is not able to be generalized to the wider population. Moreover, using one source of data rather than data triangulation could be seen as a potential threat for authenticating the results of this study. Thus, further research studies could be conducted to collect more data through individual or group interviews to validate the results. Thus, statistical analysis and the results of earlier studies regarding to data source were considered as steps to provide reliability and validity in assessing pre-service science teachers' beliefs toward pseudoscience and science discrimination.

Based on the findings of this survey study, several recommendations can be deduced. First, since these preservice science teachers had serious problems discriminating science and pseudoscience, the sources of these problems should be diagnosed in future works examining them through new variables such as religious affiliation, grade-point average, attitudes toward science, and teaching science. Second, qualitative studies focusing on the experiences of students and their belief system should be conducted to explore the sources of these problems. Finally, pre-service teachers' course structure should emphasize more issues that are pseudoscientific as well as SCI and how to discriminate science and non-science.

\section{REFERENCES}

Afonso, A.S., \& Gilbert, J.K. (2009). Pseudo-science: A meaningful context for assessing nature of science. International Journal of Science Education, 32(3), 329-348.

Allum, N. (2011). What makes some people think astrology is scientific? Science Communication, 33(3), 341-366.

Aristotle. (1996) Organon IV: Ikinci Analitikler (Atademir, H.R. Trans.). Istanbul, Turkey: Ministry of Education.

Ayvaci, H.S., \& Bag, H. (2016). Investigating the Views of Primary School Teacher Candidates' For Science Pseudo-Science Distinction. Amasya University Journal of Education Faculty, 5(2), 539-566.

Bell, R.L., \& Lederman, N.G. (2003). Understandings of the nature of science and decision making on science and technology based issues. Science Education, 87, 352-377.

Brotherton, R., French, C.C., \& Pickering, A.D. (2013). Measuring belief in conspiracy theories: The generic conspiracist beliefs scale. Frontiers in Psychology, 4, 1-15.

Cambridge Dictionaries Online. (n.d.). Citation [Def. 1]. Available from: http://www.dictionary.cambridge.org/dictionary/english/science. [Last retrieved on 2016 Nov 04].

Dorland's Medical Dictionary for Health Consumers. (2007). Elsevier, Inc. Available from: https://www.medical-dictionary.thefreedictionary.com/ science. [Last retrieved on 2017 Jan 03].

Forer, B.R. (1949). The fallacy of personal validation: A Classroom demonstration of gullibility. The Journal of Abnormal and Social Psychology, 44, 118-123.

Garrett, B.M., \& Cutting, R.L. (2017). Magical beliefs and discriminating science from pseudoscience in undergraduate professional students. Heliyon, 3(11), 1-29.

Gul, S. (2016). Prospective Biology, Physics and Chemistry Teachers' Conceptions towards Science-Pseudoscience Distinction. Journal of Theoretical Educational Science, 9(2), 177-197.

Hu, L.T., \& Bentler, P.M. (1999). Cutoff criteria for fit indexes in covariance structure analysis: Conventional criteria versus new alternatives. Structural Equation Modeling: A Multidisciplinary Journal, 6(1), 1-55.

Hurd, P.D. (1998). Scientific literacy: New minds for a changing world. Science Education, 82(3), 407-416.

Kant, I. (1855). The Critique of Pure Reason. Translated by Meiklejohn, J.M.D. London: Henry G. Bohn.

Kaplan, A.O. (2014). Research on the pseudo-scientific beliefs of pre-service science teachers: A sample from astronomy-astrology. Journal of Baltic Science Education, 13(3), 381-393.

Kirman, C.E., Lacin, Ş.C., \& Caliskan, H. (2013). The adaptation study of science and pseudoscience distinction. Trakya University Journal of Education Faculty, 3, 31-43.

Koray, M. (1993). Working Women in Turkey and Working in Public Sector Turkiye'dc Calisan Kadin ve Kamuda Calisma, Paper presented at Symposium of Women Workers in Education Sector, Ankara.

Kuhn, T.S. (1970). Logic of discovery or psychology of research. Criticism and the Growth of Knowledge. Cambridge: Cambridge University Press. pp. $1-23$.

Kuhn, T.S. (1981). The sciences as puzzle-solving traditions. In: S. C. Brown, J. Fauvel, \& R. H. Finnegan (Eds.), Conceptions of Inquiry: A Reader. London: Methuen. pp. 107-113.

Lakatos, I. (1981). Science and pseudoscience. In: Brown, S.C., Fauvel, J., \& Finnegan, R.H., (Eds.), Conceptions of Inquiry: A Reader. London, UK: Methuen. pp. 114-121.

Lambert, K., \& Brittan, G.G. (1992). An Introduction to the Philosophy of Science. $4^{\text {th }}$ ed. Atascadero, CA: Ridgeview Publishing.

Lederman, N.G. (2007). Nature of science: Past, present, and future. In: Abell, S.K., \& Lederman, N.G., (Eds.), Handbook of Research in Science Education. Mahwah, New Jersey: Lawrence Erlbaum Publishers. pp. 831-879.

Lobato, E., Mendoza, J., Sims, V., \& Chin, M. (2014). Examining the 
relationship between conspiracy theories, paranormal beliefs, and pseudoscience acceptance among a university population. Applied Cognitive Psychology, 28(5), 617-625.

Martin, M. (1994). Pseudoscience, the paranormal, and science education. Science and Education, 3(4), 357-371.

Metin, D., \& Ertepinar, H. (2016). Inferring pre-service science teachers' understanding of science by using socially embedded pseudoscientific context. International Journal of Education in Mathematics, Science and Technology, 4(4), 340-358.

Oothoudt, B. (2008). Development of an Instrument to Measure Understanding of the Nature of Science as a Process of Inquiry in Comparison to Pseudoscience. (Unpublished Master Thesis, California State University, Department of Science Education). Available from: https:// www.search.proquest.com/docview/304829166?accountid $=86205$. [Last retrieved on 2018 Sep 10].

Popper, K. (1957). Philosophy of Science. (Mace, C.A., (Ed.). British Philosophy in the Mid-Century. London: George Allen and Unwin.

Popper, K. (1963). Conjectures and Refutations. The Growth of Scientific Knowledge, London: Routledge \& Kegan Paul.

Sagan, C. (2011). Demon-haunted World: Science as a Candle in the Dark. New York: Ballantine Books.

Senler, B., \& Irven, Ö. (2016). Primary Pre-service Teachers' Epistemological
Beliefs and Pseudoscientific Beliefs. Mersin University Journal of Education Faculty, 12(2), 660-671.

Statistics of Turkish National Ministry of Education. (2013). Available from: http://www.sgb.meb.gov.tr/www/resmi-istatistikler/icerik/64. [Last retrieved on $2018 \mathrm{Sep} 12]$.

Thagard, P.R. (1978). Why astrology is a pseudoscience. In: PSA: Proceedings of the Biennial Meeting of the Philosophy of Science Association. Vol. 1. Philosophy of Science Association. pp. 223-234.

Turgut, H. (2009). Pre-service science teachers' perceptions about demarcation of science from pseudoscience. Egitim ve Bilim, 34(154), 50-68.

Turgut, H., Es, H., Altan, E.B., \& Geren, N.O. (2016). Pre-service pre-school teachers' perceptions of science and pseudo-science. International Online Journal of Educational Sciences, 8(1), 150-169.

Uslu, F. (2011). The criteria of science and problem of demarcation - science, non-science and pseudo-science. Hitit University Journal of Theology Faculty, 10(9), 5-35.

Wallis, R. (1985). Science and pseudo-science. Information (International Social Science Council), 24(3), 585-601.

Wyman, A.J., \& Vyse, S. (2008). Science versus the stars: A double-blind test of the validity of the NEO five-factor inventory and computer-generated astrological natal charts. The Journal of General Psychology, 135(3), 287-300. 